\title{
HEALTH HAZARDS OF VISUAL DISPLAY TERMINALS AMONG EXPOSED WORKERS IN SUEZ CANAL CITIES
}

\author{
By \\ Amani Waheed, Mostafa Fouad, Hoda Bassiouni \\ and Mostafa Abdel-Aziz
}

\author{
From \\ Community Medicine Department, Faculty of Medicine, \\ Suez Canal University
}

\begin{abstract}
The use of Video Display Terminals (VDTs) has increased dramatically in the past 10 years and is projected to increase. Particular concerns related to the use of VDTs include vision, dermatological, reproduction, stress and ergonomics has been directed. To evaluate the association between VDT use and the adverse conditions related to vision, musculoskeletal conditions, skin, female reproductive conditions and psychological conditions, we conducted this cross-sectional study. The study group consisted of clerical workers exposed to VDTs in Port Said, Ismailia and Suez cities for at least 12 hours weekly for at least one year. A control group selected from the same worksite with the same work-force characteristics but not exposed to
\end{abstract}

VDTs. The two groups were matched with each other as regards sex and age. The sample size turned to be 150 workers per a group. A questionnaire was used for the collection of personal and occupational data as well as health events of various body systems. Taylor and Zung self-rating scales were used for measuring anxiety and depression, respectively among our population. Screen characteristics were also asked for blood pressure and visual acuity were measured for each person included in the study. The results of this study indicated an increased prevalence of adverse conditions pertaining to musculoskeletal discomfort, menstrual disorders, visual disorders, dermatological disorders and anxiety (using Taylor self-rating scale) among clerical workers who used VDTs. While 
there was no statistically significant difference between the exposed and non-exposed groups as regards premenstrual syndrome, abortion, stillbirths, malformations and depression using Zung self-rating scale. Analysis of job factors as well as confounding factors for each health hazard is discussed. This is affected by the presence of certain job factors and contrast character of the screen of the VDTs. Good measures should be taken to improve this situation.

\section{INTRODUCTION}

With the advent of computer and information processing technologies, the use of Video Display Terminals (VDTs) is becoming increasingly widespread. It is estimated that more than 100 million workers in the United States and Canada will be using computers daily by the year 2000 (Kirsner and Fedman, 1998). According to CAPMAS (1986), the number of VDTs operators in Egypt range from 35 to 40 thousands of both sexes.

VDTs and Television sets which contain most importantly the cathode ray tubes emit $x$-rays and non-ionizing radiation in addition to magnetic and electric fields (El Samra et al., 1984). Extremely low frequency and very low frequency magnetic fields are also emitted by monochrome and multichrome video display units (Tofani and Amore, 1991).

With the rapid introduction of VDTs in many workplaces, much concern has been expressed on the impact of these devices on the operator's health. Various body systems are affected by exposure to VDTs.

Musculoskeletal discomforts occurred more frequently among VDT users. These discomforts include pain, spasms and limitation of movements (Ong, 1994; Marcus and Gerr, 1996).

Epidemiological data reviewed concern the potential reproductive effects (mainly spontaneous abortion, low birth weight and congenital malformations) of exposure to sources of electromagnetic fields mainly of occupational origin especially VDTs (Robert, 1999). Menstrual irregularities, spontaneous abortion and stillbirths were increased with exposure to VDTs (NIOSH, 1987; Nurminen and Kurppa, 1988; Mishriky et al., 1993; Grasso et al., 1997).

VDT operators have also reported 
a variety of dermatological symptoms including seborrheic dermatitis and perioral dermatitis (Stenberg et al., 1995). On the other hand, exposure to VDTs has been accused to be associated with some effects on eye and vision. These effects could be eyestrain, temporary changes in eye functions and/or pathological changes with permanent effect (Daum et al., 1988; Sheedy, 1992). From another aspect, headache, fatigue, feeling of anxiety and psychological stress are found more frequently among VDT operators (Picklet and Lees, 1991).

Studies are needed to investigate the problem of use of VDTs and its impact on the health of workers using such rapidly expanding technology. Few well-controlled studies have assessed the extent and magnitude of the adverse health conditions reported by VDT operators.

Many of the published studies, however, have been difficult to interpret because of drawbacks in the study protocols (Bergqvist, 1984). In Egypt, research in this area is scanty especially in Suez Canal area (EI Samra et al.,1984; Mishriky et al., 1993). So, our work was conducted to identify the adverse health effects of using VDTs in Suez Canal cities; Port Saied, Ismailia and Suez.

\section{SUBJECTS AND METHODS}

This cross-sectional study was conducted to identify the most prominent health problems encountered by VDT users in the three major Suez Canal cities; Port Said, Ismailia and Suez. The work sites were selected randomly from among the different places where VDTs have been widely used, e.g., Suez Canal University, schools, banks and companies.

The study population included two groups; the exposed and the nonexposed groups. The exposed group included workers using VDTs for long periods (at least 12 hours per week for at least one year), e.g., data entry and programmers. The non-exposed group: included workers in the same work sites also (for at least one year) but are not exposed to VDTs.

Workers with history of chronic diseases, neurological or psychiatric disorders were excluded.

The sample size was estimated to detect a difference in the prevalence of various health problems (related to exposure to VDTs) between exposed

MANSOURA MEDICAL JOURNAL 
and non-exposed subjects to VDTs. The prevalence of musculoskeletal symptoms among VDT users ranged from $20-25 \%$ (NIOSH/Sauter et al., 1991), while that of the eye symptoms was $13-31 \%$ (Rossignol et al., 1987). On the other hand, anxiety among VDT users ranged from $25-70 \%$ (Elias et al., 1984). The least prevalence for eye symptoms was chosen to detect a difference between exposed and non-exposed groups with a $95 \%$ confidence and a power of $80 \%$. The sample size turned to be 135 subjects per group but it was increased to 150 subjects to compensate for nonresponse.

To prevent observation bias, the study was explained to each subject as a study of the health of office workers and not as a study of the health effects associated with the use of VDTs.

A structured interview was conducted using a questionnaire for each subject in the study. Direct and closeended questions were used. The questionnaire sought information pertaining to demographic characteristics, the nature of the subjectís work including the use of VDTs, the characteristics of VDTs used e.g., contrast, design, sharpness, stability of the picture, color and presence of filters (Sauter and Schnorr, 1992). The questionnaire included questions about different health problems related to exposure to VDTs.

Blood pressure as well as visual acuity using Snellenís chart were measured at the worksites.

Questions concerning musculoskeletal symptoms covered their nature, site, frequency during the last year, any treatment and/or physiotherapy received and sick leaves due to musculoskeletal problems during the last year.

Questions concerning female reproductive system covered the nature of menstrual cycle, premenstrual syndrome, number of pregnancies, the nature of deliveries in the last pregnancy, abortion, malformation and sick leave due to reproductive problems.

Questions concerning vision covered the nature and frequency of eye complaints e.g., redness, pain, double vision, dryness and headache, wearing of eyeglasses, receiving treatment and sick leaves due to eye com- 
plaints.

Questions concerning the psychological condition covered the relationship between the subject and his/her supervisors and fellows, the work pressure, job satisfaction, sense of loneliness during work. Anxiety and depression were assessed using Taylor and Zung self-rating scales, respectively. These two scales were easy, acceptable, self-rating, short and objective.

Taylor scale measured the severity of anxiety. It was translated into Arabic by Melika (1980). A total score of less than 16 indicated no anxiety, 17-24 mild, 25-36 moderate and 3750 severe anxiety.

Zung scale (1965) measured the severity of depression. It was translated into Arabic by Okasha (1990). A total score of less than $\mathbf{5 0}$ indicated no depressive state, 51-60 mild, 6170 moderate and over 70 sever depressive state.

\section{Data Analysis:}

The relation between daily VDT use and the adverse health conditions was analyzed using Chi-squared test. The magnitude of confounders of these conditions, e.g., age, sex, residence, smoking, type of job, hours of work per day, duration of exposure per year and the characteristics of VDTs was assessed using logistic regression analysis (Harrell, 1986; Bland, 1995).

\section{RESULTS}

This study was conducted in Port Said, Ismailia and Suez cities. It comprised 150 persons exposed to VDTs and 150 control subjects. Sixty-seven exposed females and a similar number of non-exposed females were included in the study.

In the exposed group, the age ranged from 18-58 years with a mean and standard deviation of $30.9+7.6$ years; while in the control group the age ranged from 20-55 years with a mean and standard deviation of $34.2+7.6$ years with no statistically significant difference $(p>0.05)$.

Also, there were no statistically significant differences between the two groups as regards marital status, smoking habit, special hobbies, history of hospitalization or family history.

Using WHO definition of hypertension (systolic> $160 \mathrm{mmHg}$ and diastol- 
ic $>90 \mathrm{mmHg}$ ) (WHO, 1983), blood pressure measurement showed that only 6 subjects $(4 \%)$ of the exposed group were hypertensive, while 3 subjects $(2 \%)$ of the control group had systolic hypertension and $10(6 \%)$ had diastolic hypertension; but the difference was not statistically significant.

The job characteristics of the study population are shown in table 1. The characteristics of the VDTs used are shown in table 2.

The different health problems related to exposure to VDTs e.g., musculoskeletal, female reproductive system, vision, dermatological and psychological problems are shown table 3 . It depicts that anxiety and visual complaints were the most prevalent problems among our exposed group $(84.7 \%$ and $62.7 \%$, respectively).

\section{Musculoskeletal conditions:}

Musculoskeletal complaints were more frequent in the exposed group compared to the control one; the difference being statistically significant $(p<0.05)$ (table 3). In addition, back, knee and neck discomfort were significantly more frequent among VDT us- ers than the control group $(p<0.01)$. However, there was no statistically significant difference between the two groups regarding the progress of complaints, receiving treatment and physiotherapy.

To study the effect of some categorical confounders such as sex, age, residence, cities, marital status, smoking and job categories on musculoskeletal conditions backward stepwise logistic regression analysis was done (table 4). The results of the best fitting model along with the 95\% confidence intervals were for the older age group ( $>40$ years) and the duration of work. It can be noticed that the odds ratio for the duration of work per year (>10 years) is the highest.

Backward stepwise logistic regression analysis of the effect of the six characteristics of VDTs on musculoskeletal condition showed that only contrast character of VDT had an effect on the musculoskeletal conditions (table 4).

\section{Female reproductive health con-} ditions :

The mean duration of menstruation was $6.28+1.8$ days and $6.96+1.6$ days for the exposed and the non- 
exposed group, respectively, with no statistically significant difference ( $p>0.05)$. More than half of the exposed females $(50.7 \%)$ reported menstrual complaints, mainly increased amount of flow and irregularity of the cycle, while it was only $22.3 \%$ of the control group. The difference was statistically significant $(p<0.05)$. On the other hand, there was no statistically significant difference between the exposed and the control groups as regards premenstrual syndrome (PMS) (table 3).

The two groups were similar as regards the number of abortions and number of pregnancies with no statistically significant difference $(p>0.05)$. The pregnancy outcome of three cases exposed to VDTs were abnormal.

Backward stepwise logistic regression analysis was done to study the efect of categorical confounders (table 4). The effect of VDT characteristics was also analyzed using backward stepwise logistic regression. Our results showed that menstrual disorders were affected by short period of exposure (less than 5 years) and the type of job, programmers; but was not affected by VDT characteristics (table
4). However, PMS was not affected by any of the categorical confounders or VDT characteristics.

\section{Conditions related to vision:}

There was a statistically significant difference between the exposed and control groups regarding complaints related to vision $(p<0.05)$. Blurring of vision, eyestrain, headache and redness of the eyes were the most frequent complaints among subjects in both groups. Twenty six percent $(26 \%)$ of VDT users wore eyeglasses during work while $16 \%$ of the non-exposed subjects used them with a statistically significant difference $(p<0.05)$. There was statistically significant difference between the two groups as regards visual acuity as measured by Snellenís chart, even after correction by glasses. Sick leaves due to complaints of vision were significantly more frequent in the exposed group ( $p<0.05$ ); which led to more loss of work days among the exposed group.

On studying the different dependent factors against eye complaints as independent factor, it was found that work with VDTs for more than 6 hours/day aggravated eye complaints

MANSOURA MEDICAL JOURNAL 
(table 4). VDT characteristics as independent variable did not significantly affected complaints of vision as dependent factor.

\section{Conditions related to skin:}

There was a statistically significant difference between the exposed and control groups as regards dermatological complaints $(p<0.05)$. Redness and itching around the face and hands, mainly of acute onset, were the most frequent complaints in both groups. Also, there was a statistically significant difference between the two groups regarding receiving treatment and sick leaves $(p<0.05)$.

Backward stepwise logistic regression model was calculated (table 4). These complaints were affected by job type (operators) but not by VDT characteristics.

\section{Psychological conditions:}

There was a statistically significant difference between the exposed and control groups as regards job satisfaction, sense of loneliness during work and the relation with fellows $(p<0.05)$. However, there were no statistically significant differences as re- gards work pressure, and relation with supervisors. All of these relations were assessed objectively through the questionnaire.

Backward stepwise logistic regression analysis showed that the sense of loneliness during work was affected by old age ( $>40$ years) and prolonged period of work ( $>10$ years) (table 4). Work pressure was affected by smoking, hours of work per day (< 6 hours) and the duration of work (< 10 years) as shown in table (4). Job satisfaction was affected by smoking and living in urban areas as shown in backward stepwise logistic regression model (table 4).

There was a statistically significant difference between the exposed and contro I groups on measuring anxiety using Taylor self-rating scale $(p<0.01)$ as shown in table 5 . In contrast, there was no statistically significant difference between the two groups on measuring depression using Zung self-rating scale (table 6). VDT characteristics did not affect anxiety as shown on backward stepwise logistic regression model. 
Table (1) : Sociodemographic and Job characteristics of the study groups.

\begin{tabular}{|c|c|c|c|c|}
\hline & \multicolumn{2}{|c|}{$\begin{array}{c}\text { Exposed } \\
(n=150)\end{array}$} & \multicolumn{2}{|c|}{$\begin{array}{c}\text { Non-exposed } \\
(n=150)\end{array}$} \\
\hline & Frea & $\%$ & Freq & $\%$ \\
\hline $\begin{array}{l}\text { Age: } \\
\quad X \pm S D\end{array}$ & \multicolumn{2}{|c|}{$30.9 \pm 7.6$} & \multicolumn{2}{|c|}{$34.2 \pm 7.6$} \\
\hline $\begin{array}{ll}\text { Sex: } & \\
& \text { Males } \\
& \text { Females }\end{array}$ & $\begin{array}{l}83 \\
67\end{array}$ & $\begin{array}{l}55.3 \\
44.7\end{array}$ & $\begin{array}{l}83 \\
67\end{array}$ & $\begin{array}{l}55.3 \\
44.7\end{array}$ \\
\hline $\begin{array}{c}\text { Marital Status: } \\
\text { Married } \\
\text { Single } \\
\text { Divorced }\end{array}$ & $\begin{array}{l}91 \\
56 \\
3\end{array}$ & $\begin{array}{r}60.7 \\
37.3 \\
2.0\end{array}$ & $\begin{array}{c}97 \\
51 \\
2\end{array}$ & $\begin{array}{c}64.7 \\
340 . \\
1.3\end{array}$ \\
\hline $\begin{array}{l}\text { Residence: } \\
\text { Urban } \\
\text { Rural }\end{array}$ & $\begin{array}{c}116 \\
34\end{array}$ & $\begin{array}{l}77.3 \\
22.7\end{array}$ & $\begin{array}{c}124 \\
26\end{array}$ & $\begin{array}{l}82.7 \\
17.3\end{array}$ \\
\hline $\begin{array}{l}\text { Job type: } \\
\text { " operators } \\
\text { "programmers }\end{array}$ & $\begin{array}{r}113 \\
37\end{array}$ & $\begin{array}{l}75.3 \\
24.7\end{array}$ & -. & $\begin{array}{l}. \cdot \\
. \cdot\end{array}$ \\
\hline $\begin{array}{c}\text { Duration of work (years): } \\
=-1 \\
=5- \\
* 10-\end{array}$ & $\begin{array}{l}37 \\
76 \\
37\end{array}$ & $\begin{array}{l}24.7 \\
50.7 \\
24.6\end{array}$ & $\begin{array}{l}44 \\
30 \\
66\end{array}$ & $\begin{array}{l}29.3 \\
20.0 \\
50.7\end{array}$ \\
\hline $\begin{array}{l}\text { Duration of work/day } \\
\text { (hours): } \\
:<3 \\
: 3- \\
=6-\end{array}$ & $\begin{array}{l}35 \\
64 \\
51\end{array}$ & $\begin{array}{l}23.3 \\
42.7 \\
34.0\end{array}$ & $\begin{array}{c}0 \\
50 \\
100\end{array}$ & $\begin{array}{c}0.0 \\
33.3 \\
66.7\end{array}$ \\
\hline $\begin{array}{l}\text { Rest time during work: } \\
\text { * Yes } \\
\text { * No }\end{array}$ & $\begin{array}{c}104 \\
46\end{array}$ & $\begin{array}{l}69.3 \\
30.7\end{array}$ & $\begin{array}{c}8 \\
142\end{array}$ & $\begin{array}{c}5.4 \\
94.6\end{array}$ \\
\hline $\begin{array}{l}\text { Private work with VDTs: } \\
\text { Yes } \\
\text { No }\end{array}$ & $\begin{array}{r}20 \\
130\end{array}$ & $\begin{array}{l}13.3 \\
86.7\end{array}$ & 150 & $\overline{100}$ \\
\hline $\begin{array}{l}\text { Vacation during work: } \\
\text { "Yes } \\
\text { - No }\end{array}$ & $\begin{array}{l}64 \\
86\end{array}$ & $\begin{array}{l}42.7 \\
57.3\end{array}$ & $\begin{array}{c}4 \\
146\end{array}$ & $\begin{array}{l}2.7 \\
97.3\end{array}$ \\
\hline
\end{tabular}


Table (2) : Characteristics of VDTs used.

\begin{tabular}{|c|c|c|}
\hline VDT character & $\begin{array}{l}\text { frequency } \\
(n=150)\end{array}$ & $\%$ \\
\hline $\begin{array}{l}\text { 1- Contrast: } \\
\qquad \begin{array}{l}* \text { Good } \\
* \text { Not appropriate }\end{array}\end{array}$ & $\begin{array}{c}107 \\
43\end{array}$ & $\begin{array}{l}71.3 \\
28.7\end{array}$ \\
\hline $\begin{array}{l}\text { 2- Design: } \\
\text { * Good } \\
* \text { Bad }\end{array}$ & $\begin{array}{l}99 \\
51\end{array}$ & $\begin{array}{l}66.0 \\
34.0\end{array}$ \\
\hline $\begin{array}{l}\text { 3- Sharpness: } \\
\text { * Sharp } \\
\text { * Not sharp }\end{array}$ & $\begin{array}{c}102 \\
48\end{array}$ & $\begin{array}{l}68.0 \\
32.0\end{array}$ \\
\hline $\begin{array}{l}\text { 4- Stability: } \\
\qquad \text { Stable } \\
\text { - Not stable }\end{array}$ & $\begin{array}{l}105 \\
45\end{array}$ & $\begin{array}{l}70.0 \\
30.0\end{array}$ \\
\hline $\begin{array}{l}\text { 5- Color: } \\
\text { * Colored } \\
\text { * Not colored }\end{array}$ & $\begin{array}{l}103 \\
47\end{array}$ & $\begin{array}{l}68.7 \\
31.3\end{array}$ \\
\hline $\begin{array}{c}\text { 6- Use of filter: } \\
\text { * Yes } \\
\text { * No }\end{array}$ & $\begin{array}{l}72 \\
78\end{array}$ & $\begin{array}{l}48.0 \\
52.0\end{array}$ \\
\hline
\end{tabular}

Table (3) : Various health problems among exposed and non-exposed groups.

\begin{tabular}{|l|c|c|c|c|c|c|}
\hline \multirow{2}{*}{ Health problem } & \multicolumn{2}{|c|}{ Exposed } & \multicolumn{2}{c|}{ Non-exposed } & \multirow{2}{*}{ X2 } & \multicolumn{1}{c|}{$p$} \\
\cline { 2 - 6 } & frequency & $\%$ frequency & $\%$ \# & & \\
\hline Musculoskeletal complaints & 50 & 33.3 & 31 & 20.7 & 6.11 & $0.01^{*}$ \\
Menstrual disorders & 34 & 50.7 & 15 & 22.3 & 5.8 & $0.02^{*}$ \\
Premenstrual syndrome & 32 & 47.8 & 34 & 50.7 & 6.55 & 0.26 \\
Visual complaints & 94 & 62.7 & 53 & 35.3 & 22.42 & $0.00^{*}$ \\
Dermatological complaints & 36 & 24.0 & 17 & 11.3 & 8.27 & $0.004^{*}$ \\
Psychological complaints: & 127 & 84.7 & 81 & 54.0 & 20.79 & $0.00^{*}$ \\
* Anxiety & 8 & 5.3 & 8 & 5.3 & 0.00 & 1 \\
\hline
\end{tabular}

\# The percentage could not be added to $100 \%$

* Statistically significant at $5 \%$ level of significance.

Vol. 30 , No. 1 \& 2 Jan. \& April, 2000 
Table (4) : Backward stepwise logistic regression analysis and odds ratio of musculoskeletal complaints

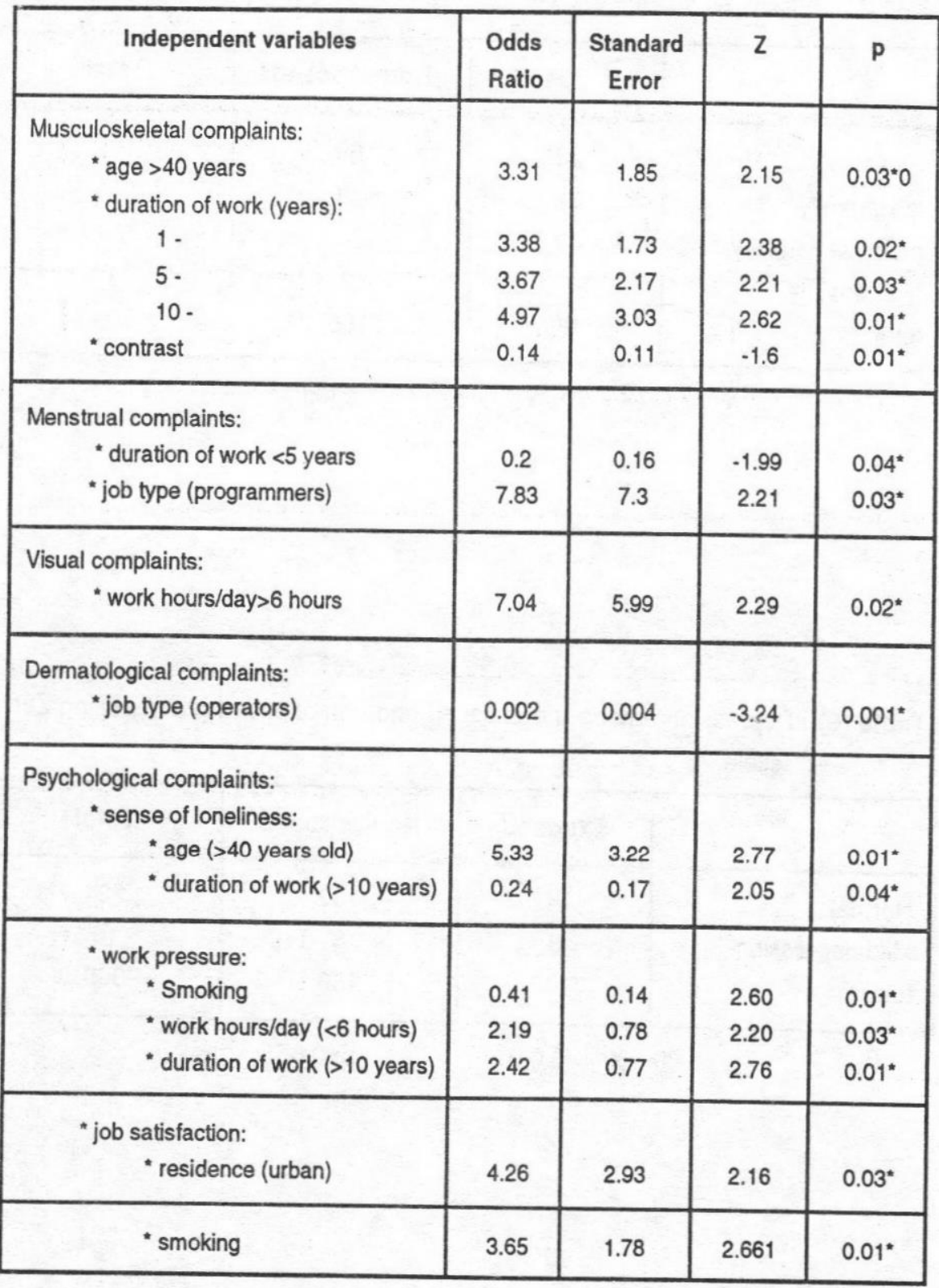


Table (5) : Anxiety among the exposed and non-exposed groups using Taylor scale .

\begin{tabular}{|l|c|c|c|}
\hline & Exposed & Non-exposed & Total \\
\hline no anxiety & 33 & 69 & 102 \\
low anxiety & 62 & 49 & 111 \\
moderate anxiety & 49 & 30 & 79 \\
high anxiety & 6 & 2 & 8 \\
total & 150 & 150 & 300 \\
\hline \multicolumn{3}{|c|}{} \\
\cline { 2 - 2 }
\end{tabular}

Table (6) : Depression among the exposed and non-exposed groups using Zung scale.

\begin{tabular}{|l|c|c|c|}
\hline & Exposed & Non-exposed & Total \\
\hline Normal & 142 & 142 & 284 \\
Mild depression & 8 & 8 & 16 \\
total & 150 & 150 & 300 \\
\hline \multicolumn{3}{|c|}{$\mathrm{X}^{2}=0.0 .0$} & $\mathrm{p}>0.05$
\end{tabular}

Vol. 30, No. 1 \& 2 Jan. \& April, 2000 


\section{DISCUSSION}

Our findings support the results of previous studies with respect to increased prevalence of adverse conditions pertaining to musculoskeletal symptoms, menstrual disorders, vision, skin and anxiety among workers in clerical positions who use VDTs in Port Said, Ismailia ands Suez cities.

\section{The Musculoskeletal Condi-} tions:

The present study does suggest that clerical workers who use VDTs are at an increased risk of developing musculoskeletal symptoms with a prevalence of $33.3 \%$. These symptoms are in the form of pain, parasthesia and limitation of movement. This finding agrees with the result reported by NIOSH / Sauter et al., (1991) where $20-25 \%$ prevalence rate of almost daily discomfort of musculoskeletal disorders. Also, NIOSH (1990) found $40 \%$ of participants reported symptoms that met the definition of cumulative trauma disorders. Back, knee and neck discomforts were most frequent among our VDTs users. Rossignal et al., (1987) found that neck pain followed by shoulder pain were the most prevalent musculoskeletal symptoms. Ong (1994) found that musculoskeletal discomfort of the hands and arms were common among VDT operators. In a recent study (Mbaye et al., 1998), $82.9 \%$ of complaints related to musculoskeletal disorders were mainly located in the low back, the neck and the shoulders. On the other hand, Sauter (1984) and Griceo et al., (1989) showed no significant increase in musculoskeletal symptoms among VDT users.

Neither sex nor job type affected musculoskeletal complaints among our population; while symptoms increased among older VDT users. This may be due to normal aging process during which musculoskeletal complaints increased. This was more evident especially if we noticed that aging is the main factor affecting musculoskeletal symptoms. The musculoskeletal symptoms were not affected by duration of exposure per day nor the duration of work in years, while another study (Bergqvist and Knave, 1994) reported that VDT female operators tended to have more symptoms than male operators. On the other hand, some studies (Evans, 1986; Rossignol et al., 1987) found that musculoskeletal symptoms increased at 5 hours VDT work or more per day.

MANSOURA MEDICAL JOURNAL 
The current study showed tha contrast of the VDT increased musculoskeletal complaints among our VDT users due to incorrect posture with these inappropriate characters. Mbaye et al., (1998) found that ergonomics appeared to be the main cause of musculoskeletal symptoms.

The musculoskeletal symptoms among VDT users in this study were not severe enough and not disabled the employees to take off the job through sick leaves in contrast to Bergenudd et al., (1988) where they reported that $3 \%$ had been on sick leave because of shoulder pain in the year preceding the examination.

The musculoskeletal conditions among VDT users might result from constrained posture and static loading of muscles as well as poor contrast character of VDT in this study. However, no evidence of skeletal or neurological injury was shown. Ergonomics as well as clinical studies should be done to investigate this problem.

\section{Reproductive Health Condi- tions: \\ Menstrual problems were studied because they are considered as fur- ther possible indicators of an adverse}

reproductive effect (Joffe, 1989). The study of reproductive problems among VDT users revealed significantly higher rates of menstrual disorders than the non-exposed subjects. Menstrual irregularity and menorrhagia were more frequent among VDT users. Mishriky et al., (1993) found that menstrual irregularity and dysmenorrhea were higher among exposed subjects.

Our findings showed that menstrual disorders were affected by short duration of exposure ( $<5$ years) and the job type of programmers. This may be due to low frequency and extremely low frequency electromagnetic fields emitted from VDTs (Mishriky et al., 1993) while increase manifestations among programmers may be due to physical and/or mental stress.

As regards premenstrual syndrome (PMS), there was no statistically significant difference between exposed and non-exposed subjects. In contrast, Mishriky et al., (1993) reported that there was a statistically significant difference between exposed and non-exposed females as regards PMS. In this work, PMS was not affected by confounding factors and VDT characteristics. There was 
lack of literature discussing menstrual disorders and PMS among VDT users. These will need further studies.

In this study, abortion rates were similar in the exposed and nonexposed groups. This finding agrees with Kajiwara (1984). In their two-year study which covered $90 \%$ of all deliveries in Montreal area, Marriot and Stuchly (1986) did not observe any significant correlation between VDTs use and spontaneous abortion. Similarly, Bryant and Love (1989) in a case-controlled study, found an odds ratio of 1.14 but it was not significant. Also, Nielson and Brandt (1990) and Schnorr and his group (1991) found no association between spontaneous abortion and exposure to VDTs. In contrast, McDonals et al., (1986) found that the percentage of abortion was higher among VDT users with a statistically significant difference. Goldhaber et al., (1988) found increased risk of spontaneous abortion among workers exposed to VDTs.

The lack of association between exposure and the occurrence of spontaneous abortion could be a true finding or might be due to the small number of these events in the studied sample and may be due to recall bias.
All of the available epidemiologic studies have limitations that prevented them from drawing a clear-cut conclusion on the effect of EMFs on human reproduction (Robert, 1999). So, further investigations are needed.

In this study, the pregnancy outcome of three cases exposed to VDTs was abnormal. Knilljones (1984) failed to adjust for factors known to affect pregnancy outcome as menstrual age, parity and smoking. Our available data does not support the existence of a link between VDT exposure and adverse reproductive outcomes.

\section{Conditions related to Vision:}

As regards eye discomfort, there was a statistically significant difference between the exposed and nonexposed groups of our population. These discomforts were mainly in the form of eye strain, headache and blurring of vision. The symptoms increased with increased daily work duration ( $>6$ hours) where more exposure to VDT occurred with increased daily office work. Other confounders had no weight on increasing visual complaints. Increased prevalence of symptoms related to vision include adverse effects of glare and 
constant focus on the eye in addition to increased daily work hours.

Several studies found a higher prevalence of eye discomfort or asthenopia among VDT users compared to non-VDT users (Kajiwara 1984; Knave et al., 1985). In a Japanese study (Nakaishi and Yamada, 1999) 242 subjects from 722 VDTs workers had symptoms of asthenopia. The incidence of visual and ocular asthenopia in VDTs workers ranged from $10 \%$ up to $70 \%$ depending on the individual characteristics as well as type of job (35 and 43), while Rossignal et al., (1987) showed that the prevalence of visual discomfort ranged from $13 \%$ to $31 \%$ according to daily hours of exposure to VDTs. Bergqvist and Knave (1984) supported this finding of increasing eye manifestations with VDT work or VDT work duration. So the time looking at the screen could be a primary factor in determining asthenopia as described by Knave et al., (1985).

It should be noted that the mean ages of our population were $30.9+7.6$ and $34.2 \pm 7.6$ for the exposed and non-exposed groups, respectively. This situation may make comparability with other studies less clear-cut
(Ong et al., 1990) because they found that visual complaints were more frequent among older (31-49 years old) than younger (18-30 years old) VDT operators. It was explained by aging process and occurrence of presbyopia with improper correction.

On the other hand, other investigators (De Groot and Kamphius, 1983; Smith et al., 1984) failed to clarify the association between eye discomfort and current extent of VDT use. Another investigator did not find association between redness or sensitivity to light and VDT work (Belisario et al., 1988). Also, Lewis et al., (1992) did not find statistically significant differences between VDTs users and non-users as regards incidence of asthenopia.

The visual acuity after correction of both exposed and non-exposed groups was fairly good with no statistically significant difference. The use of glasses among VDT users was significantly more frequent than among non-users. This may be due to eye manifestations due to exposure to VDTs (Bergqvist and Knave, 1994).

Sick leaves due to eye complaints were significantly more frequent 
among VDT users. This agrees with Rossignal et al., (1987) where few subjects reported missing work because of vision condition. VDT characteristics did not affect our results while Gobba et al., (1988) found that contrast and illumination conditions seemed to be of paramount importance regarding visual symptoms.

\section{Conditions related to Skin:}

This study detected a statistically significant tendency for increasing dermatological complaints among VDTs users than non-users. These complaints were mainly in the form of redness and itching. Bergqvist and Wahlberg (1994) reported that there were increased occurrence of seborrheic eczema and non-specific erythema among VDT users. Seborrheic dermatitis, acne and perioral dermatitis were more frequent among VDT operators in another study (Knave et al., 1985). Stenberg et al., (1995) reported that VDTs were one of the factors leading to increased prevalence of facial skin symptoms among VDT workers. Their results suggested that skin symptoms among VDT workers had a multifactorial background. On the other hand, some investigatots failed to show any association between exposure to VDTs and objec- tive skin manifestations (Lid and Berg, 1991).

In this study, it was found that VDT operators (as a job type) suffered more from dermatological problems. VDT characteristics had no weight on dermatological conditions among VDT users. The non-exposed group received treatment for dermatological complaints significantly more than the exposed group. Also, sick leaves due to skin problems were of significantly longer duration among the nonexposed group than the exposed one. This may be due to the nature of the dermatological problems which force people to seek medical assistance or may be due to work characteristics of the exposed and non-exposed groups, where production and sick leave were the main outcome of their work and income.

Rycroft et al., (1984) reported that electrostatic fields of VDT enhanced particle deposition on the workersí faces. Skin reaction to these contaminants might occur in susceptible ind;viduals. Lid and Berg (1991) concluded that there was nothing in their or in any other investigation that would speak against the notion that VDTrelated skin problems and the allergy 
to electricity is just another facet of the $20^{\text {th }}$ century syndrome.

\section{Psychological Conditions:}

This work detected a statistically significant difference between VDT users and non-users as regards sense of loneliness during work, relationship with fellows, work pressure and job satisfaction; while there was no statistically significant difference between the two groups as regards the relationship with their supervisors. NIOSH studies (1981; 1982) showed that in contrast to peers who did not use VDTs, VDT users reported increased work pressure, reduced autonomy and increased management control over work processes. They also showed increased disruptions in work relationships between VDT users and their peers and supervisors. However, Aborg and his group (1998) reported that the work content even after reorganization still did not provide satisfactory mental variation for most of the subjects exposed to VDTs.

In this work, sense of loneliness during work was affected by old age ( $>40$ years) and prolonged duration of work (>10 years). Work pressure was also affected by prolonged duration of work ( $>10$ years), increased work hours per day ( $>6$ hours), living in urban areas and lastly smoking. Smoking was also a confounder on examination of job satisfaction among our population. All these elements may lead to excessive repetition and physical and mental stress. NIOSH studies $(1981 ; 1982)$ showed disruptions in working relationship between VDT users and their peers and supervisors. The relationship between our VDT users and their supervisors was good, while their relationship with their peers was disrupted. This may be due to more conservative relationship with supervisors, which may be related to different issues.

The present study showed that there was a statistically significant difference between exposed and nonexposed groups on measuring anxiety using Taylor self-rating scale, while there was no statistically significant difference between the two groups on measuring depression using Zung self-rating scale. Taylor as well as Zung scales are standardized, valid and reliable tests used in Egyptian population after Melika (1980) and Okasha (1990), respectively. Screen characteristics had no effect on measuring anxiety among our VDTs users.

Vol. 30 , No. $1 \& 2$ Jan. \& April, 2000 
Other studies showed that high occurrence of psychological disturbances among VDT operators (ILO/WHO, 1984). Such disturbances included anxiety, irritability and depression. Elias et al., (1984) detected an incidence of $25 \%$ to $70 \%$ among VDT operators, which agrees with the present results. Smith (1997) gave light on psychological aspect of VDT users where job stress and their consequences for mental and physical heaIth were emerging among VDT users.

To conclude, this study has demonstrated a statistically significant difference between VDTs users and non-users as regards musculoskeletal complaints, menstrual disorders, visual complaints, dermatological complaints and some psychological complaints. Education regarding the significance of these issues becomes a key form of intervention. Ergonomic changes should be done to reduce or eliminate damage to the health of VDT operators. The job must be designed to fit the physical, behavioral and psychological limitations as well as the anthropometric and biochemical characteristics of workers. A preventive action of multidisciplinary approach is needed in order to arrive at improved methods for identifying and evaluating health problems related to the use of visual display terminals. Further studies should be conducted in depth taking in consideration avoidance of different methodological problems.

\section{REFERENCES}

Aborg C, Fernerstorm E, Ericson MO. (1998) : Work content and satisfaction before and after a reorganization of data entry work. Appl Ergon Dec., 29(6):473-80.

\section{Belisario A, Modiano A, Fantini A, Gennari E, Nini D, Bachhi L. (1988) : Ocular symptoms and video display terminals: research work on a VDT op- erators group. J Ital Med., 10:39-42.}

Bergenudd $\mathrm{H}$, Lindgarde $\mathrm{F}$, Nilsson B, Petersson CJ. (1988) : Shoulder pain in middle age. A study of prevalence and relation to occupational work load and psychosocial factors. Clin Orthop. Jun; (231):234-8.

Bergqvist $U O$ and Knave BG. (1994) : Eye discomfort MANSOURA MEDICAL JOURNAL 
and work with visual display terminals. Scand J Work Environ Health. 20 (1) : 27-33.

Bergqvist UOV. (1984) : Video display terminals and health: $A$ technical and medical appraisal of the state of the art. Scand. J. Work Environ. Health. ; 10:1-87.

Bergqvist UO, Wahlberg JE. (1994) : Skin symptoms and disease during work with visual display terminals. Contact Dermatitis, 30(4):197-204.

Bland M. (1995) : An introduction to medical statistics. $2^{\text {nd }}$ ed. Oxford University Press.

Bryant HE, Love EJ. (1989) : Video display terminal use and spontaneous abortion risk. Inter J Epidemiol., 18(2):132.

CAPMAS (1986) : Census for Population, Housing and Establishments, Ref No. 873/91/ CAC, p. 169.

Daum KM, Good G, Tijerina L. Vol. 30, No. 1 \& 2 Jan. \& April, 2000
(1988) : Visual complaints and video display terminals. N Y State J Med, 14:289-90.

De Groot JP, Kamphius A. (1983) : Eyestrain in VDU users: physical correlates and long term effects. Hum Factors; 25:409-13.

El Samra GH, Emara AM, Emara MF, AbuAali AN, Tolba F, Tolba SH. (1984) : Irradiation Hazards in Television Industry. Egypt J Occup Med, 3:2, 223-6.

Elias R, Cail F, Tisserand M. (1984) : Investigations in operators working with CRT display terminals. In Grandjean E, Viglianil E (eds.) iErgonomic Aspects of Visual Display Terminalsî London, Taylor and Francis, pp. 211-217.

Evans J. (1986) : Questionnaire survey of British VDU operators. In: iProceedings of an International Scientific Conference. Work with Display Units". Stockholm, 566-568. 
berto F, Cavalleri A. (1988)

: Visual fatigue in video display terminal operators: objective measure and relation to environmental conditions. Int Arch Occup Environ Health, 60:81-7.

Goldhaber MK, Polen MR, Hiatt RR. (1988) : The risk of miscarriage and birth defects among women who use visual display terminals during pregnancy. Am J Ind Med., $13 L 965$.

\section{Grasso P, Parazinni F, Chatenoud} L, Di Cintio E, Benzi G. (1997) : Exposure to video display terminals and risk of spontaneous abortion. 1997. Am J Ind Med, 324:403-7. Oct.

\section{Griceo E, Occhipinti S, Colombini}

D. (1989) : Work postures and musculoskeletal disorders in VDT operators. Bolletino Oculistica, 68:99-112.

Harrell FE. (1986) : The logist procedure: SUGI supplemental library user's guide, version 5 edition.
Cary NC.: SAS Institute.

ILO/WHO Report of the Joint ILO/ WHO Committee on Occupational Health. (1984) : Ninth Session on Recognition and Control of Adverse Psychological Factors at Work. Geneva, International Labour Office.

Joffe M. (1989) : Male and female mediated reproductive effects of occupation. The use of questionnaire methods. $J$ Occup Med., 31(12):974.

Kajiwara S. (1984) : Work and health in VDT workplaces. In: "Service Training Institute for Safety and Health of Labour". Osaka. Pp. 5-12.

Kirsner RS and Fedman DG. (1998) : Video display terminals: risk of electro-magnetic radiation. South Med J, 91:12-6. Jan.

Knave BG, Fitz J, Pastis P. (1985a)

: Work at video display terminals. An epidemiological health investigation of office employees. Scand J Work

MANSOURA MEDICAL JOURNAL 
Environ Health, 11:457-466.

Knillijones RP. (1984) : Adverse pregnancy outcomes amongst lady doctors. Lessons from twelve years of research. In: iProceedings of an International Meeting to Examine the Allegations of Reproductive Hazards from VDUs. London, pp. 177185.

Lewis $F$, Esterman A, Dorsch $M$. (1992) : A survey of the heath consequences to females of operating visual units. Community Health Studies, 6:130-134.

Lid S, Berg M. (1991) : Skin problems in users of video display terminals. Discrepancy between subjective symptoms and objective signs. Acta Derm Venerol Supp (Stockh), 257:18-22.

Marcus M and Gerr F. (1996) : Upper extremity musculoskeletal symptoms among female office workers: association with video display terminal use and occupational psy- chological stressors. Am J Ind Med. 29:161-70.

Marriot JA, Stuchly MA. (1986) : Health aspects of work with visual display terminals. $\mathrm{J}$ Occup Med., 28(9):833.

Mbaye I, Fall MC, Sagnon A, Sow ML. (1998) : Survey of pathology associated with the use of video display terminals. Dakar Med., 43(1):3740.

Mc Donalds AD. (1986) : Birth defects, spontaneous abortion and work with VDTs. In: -Proceedings of an International Scientific Conference, Work with Display Unitî Stockholm. Pp. 669-670.

Melika LK. (1980) :

Mishriky AM, Mouselhy MS, Fouad MA. (1993) : A study of reproductive problems among workers exposed to video display terminals with emphasis on spontaneous abortion. Med J Cairo Univ., 61(2):519-525.

Vol. 30 , No. $1 \& 2$ Jan. \& April, 2000 
Nakaishi H, Yamada Y. (1999) : Abnormal tear dynamics and symptoms of eye strain in operators of visual display terminal. Occup Environ Med., 56:6-9.

Nielsen CV, Brandt LPA. (1990) : Spontaneous abortion among women using video display terminals. Scand $J$ Work Environ Health, 16:223-8.

NIOSH Publications on Video Display Terminals. Cincinati. (1987) : National Institute for Occupational Safety and Health.

NIOSH. Cincinati OH. (1990) : National Institute for Occupational Safety and Health. HETA 89-250-2046.

NIOSH/Sauter SL, Gottlieb MS, Jones KC, Dodson VN, Rohrer KM. (1982) : Job and health implications of VDT use: initial results of the Wisconsin NIOSH study. Comm Assoc Comput Machinery, 26:284-294.
NIOSH/Sauter SL, Schleifer LM, Knutson SJ. (1991) : Work posture, work design and musculoskeletal discomfort in a VDT data entry task. Hum. Factors; 33:151-167.

NIOSH/Smith MJ, Cohen BGF, Stammerjohn LW. (1981) : An investigation of health complaints and job stress in video display operation. Hum Factors, 23:387-400.

Nurminen T and Kurppa K.(1988) : Office employment, work with video display terminals and course of pregnancy Reference mothersí experience from a Finnish casereferent study of birth defects. Scand J Work Environ Health, 14:293-8. Oct.

Okasha A. (1990) : Depressive morbidity in an Egyptian population. Egypt J. Psychiatry. 13:131-133 .

Ong $\mathrm{CN}$, Thein MM, Bergqvist U. (1990) : A review of adverse effects on reproduction among computer terminal workers. Ann. Acad. Med. 
Singapore. 19(5):649-55.

Ong CN. (1994) : Musculoskeletal disorders in operators of video display terminals. World Heatth Forum, 15(2):161-4.

Picklet CW and Lees RE. (1991) : A cross-sectional study of health complaints among 79 data entry operators using video display terminals. $J$ Soc Occup., 10:113-6.

Robert E. (1999) : Intrauterine effects of electromagnetic fields (low frequency), mid frequency RF and microwave: review of epidemiologic studies. Teratology, 59 (4):292-8.

Rossignol AM, Morse EP, Summers VM, Pagnotto LD. (1987) : Video display terminal use and reported health symptoms among Massachusetts clerical workers. J Occup Med., 29:112-8.

Rycraft RJ, Calinam CD. (1984) : Facial rashes among visual display unit (VDU) operators. In Pearce BG (ed.):
"Health Hazars of VDTs" Chichester Wiley, pp. 134135.

Sauter S. (1984) : Predictors of strain in VDT users and traditional office workers. In Granjean E (ed.) Ergonomic and HeaIth in Modern Offices. London, Taylor and Francis. pp. 129-135.

Sauter SL, Schnorr TM. (1992) : Occupational health aspect of work with video display terminals. In: "Environmental and Occupational Medicine", Rom W (ed.). $2^{\text {nd }}$ ed. Little Brown and Company, Chapter 94, pp. 1109-1119.

Schnorr TM, Grajewski BA, Hornung RW et al., (1991) : Video display terminal and the risk of spontaneous abortion. N Eng J Med., 324:727-733.

Sheedy JF. (1992) : Vision problems at video display terminals: a survey of optometrists. J. Am Optom Assoc., 18:68792. Oct. 
Smith AB, Tanaka S, Halperin W. (1984) : Correlates of ocular and somatic symptoms among video display terminal users. Hum. Factors; 26:143-156.

Smith MJ. (1997) : Psychosocial aspects of working with video display terminals (VDTs) and employee physical and mental health. Ergonomics, 40:1002-15.

Stenberg B, Eriksson N, Mild KH, Hoog J, Sandstrom M, Sundell J, Wall S. (1995) : Facial skin symptoms in visual display terminal (VDT) workers. A case referent study of personal, psycho- social, building $\tilde{n}$ and VDT related risk indicator. Int $\mathrm{J}$ Epidemiol, 24:796-803. Aug.

Tofani and Amore (1991) : Extremely low frequency and very low frequency magnetic fields emitted by video display units. Bioelectromagnetics, 32:35-45.

WHO Technical Report Series, No 686: (1983) : Primary prevention of essential hypertension. Geneva: World Health Organization.

Zung W. (1965) : A self-rating depression scale. Arch. Psychiatry, 12:63-70. 
المخاطر الصحى لدى العمال المعرضين لشاشات

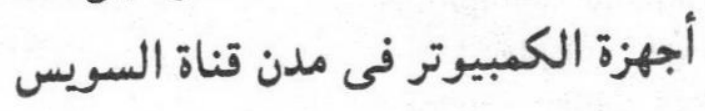

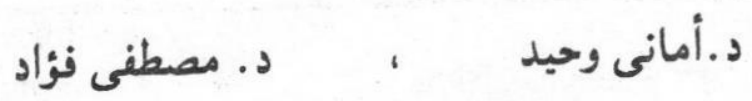

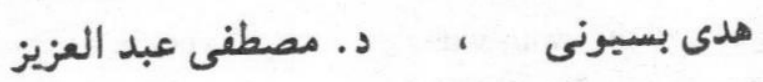

$$
\begin{aligned}
& \text { تسم طب المجتعع - كلية الطـب - جامع تناة السويس }
\end{aligned}
$$

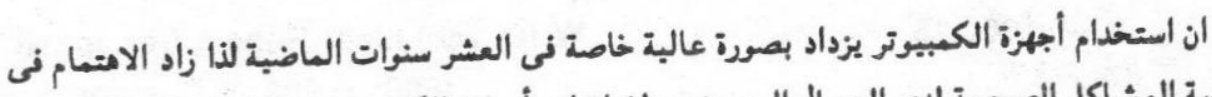

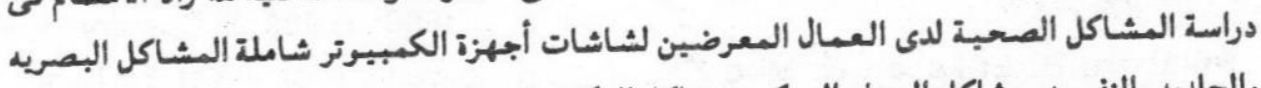

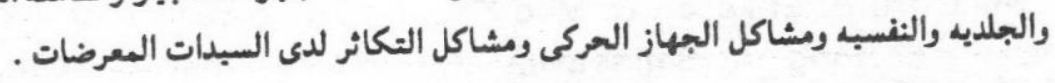

يهدف هذا البحث إلى دراسة هذه المشاكل الصحبة وعلاتتها بالتعرض الى شاشات أجهزة الكمبيوتر.

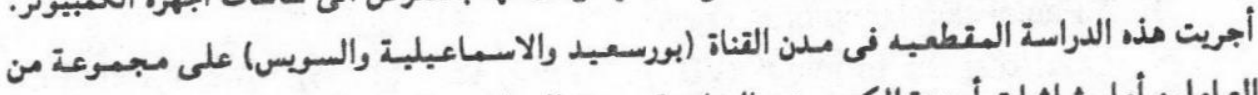

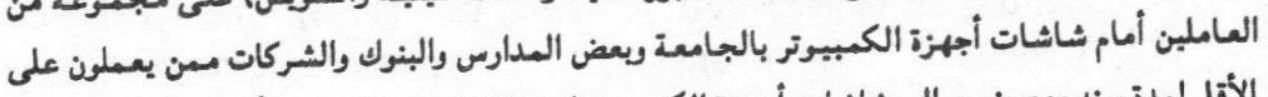

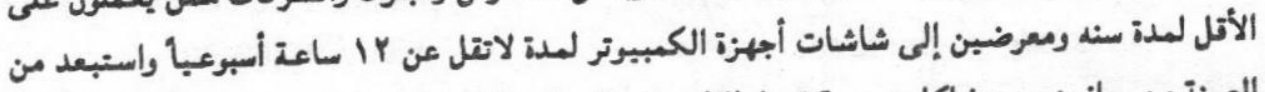

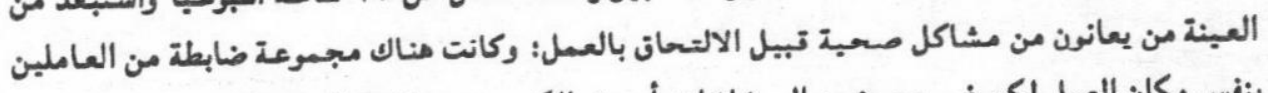

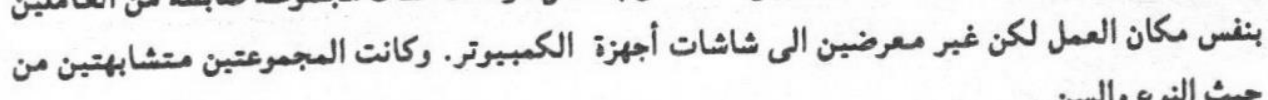

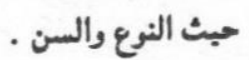

وتم حساب حجم العبنة بـ ـ 10 شخصا لكل من المجموعتين. ولثد تم إستخدام إستمارة إستبيان

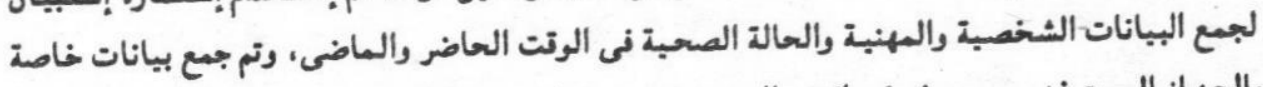

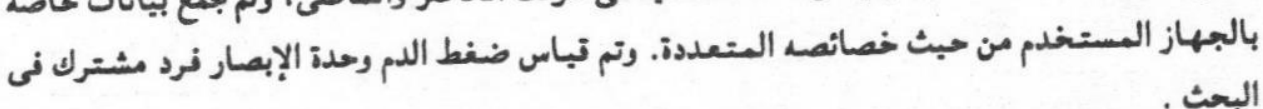

وأوضعت النتانج أن هناك نروق ذات دلالة إحصائبة بين السعرضين إلى شاشات أجهزة الكمبيوتر

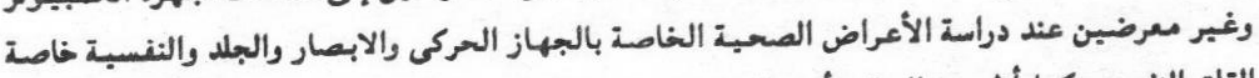

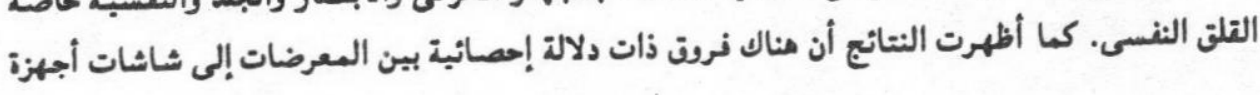


الكمبيوتر وغبر المعرضات عند السؤال عن المشاكل الصحية الخاصة بالطمث. لكن لم يكن هناك إختلافا. ذا دلالة إحصاثبة عند دراسه أعراض زمله ماتبل الطمث والإجهاض وتشومات السوات الأجنة.

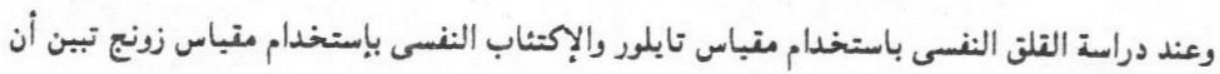

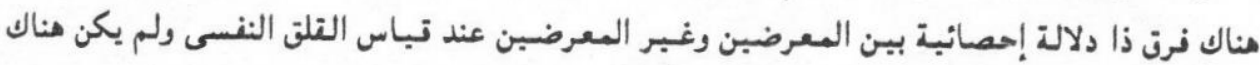

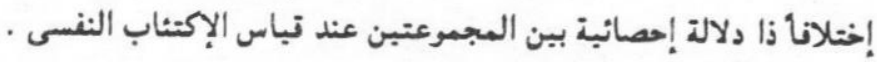

وعند دراسة عرامل التشويش باستـخدام تحليل النكوص وجد أن بعض هذه الأعراض الصحية تتأثر بالسن ونترة العمل وعدد ساعات العمل البومية وخاصية التضاد للأجهزة المستخدمة. لذا وجب توجبه الإمتهام لتحديد هذه المشاكل الصحبة بطريقة موضوعبة وتحليلية ودراسة العوامل المتعلقة بها خاصة بيثة العمل كلية . 
